\title{
FERLAND, Philippe, Paul Gouin. Montréal, Guérin Éditeur, 1991. 604 p.
}

\section{Marcel Caya}

Volume 47, numéro 3, hiver 1994

URI : https://id.erudit.org/iderudit/305271ar

DOI : https://doi.org/10.7202/305271ar

Aller au sommaire du numéro

Éditeur(s)

Institut d'histoire de l'Amérique française

ISSN

0035-2357 (imprimé)

1492-1383 (numérique)

Découvrir la revue

Citer ce compte rendu

Caya, M. (1994). Compte rendu de [FERLAND, Philippe, Paul Gouin. Montréal, Guérin Éditeur, 1991. 604 p.] Revue d'histoire de l'Amérique française, 47(3),

461-463. https://doi.org/10.7202/305271ar d'utilisation que vous pouvez consulter en ligne.

https://apropos.erudit.org/fr/usagers/politique-dutilisation/ 
FERLAND, Philippe, Paul Gouin. Montréal, Guérin Éditeur, 1991. 604 p.

Contrairement à ce que laisse croire le titre, cet ouvrage n'est pas une biographie de Paul Gouin. Il s'agit plutôt des «souvenirs» évoqués par Philippe Ferland de sa participation à l'épisode de l'Action libérale nationale aux côtés de Paul Gouin. Au terme d'une carrière de juriste, Ferland livre ainsi son propre témoignage afin de corriger, espère-t-il, les impressions laissées par les historiens qui, par omission, ont fait outrage «aux mérites de Paul Gouin». Le bouquin de presque 600 pages s'ouvre sur une brève description des racines familiales de Paul Gouin, mais n'amorce directement son propos qu'à partir de 1932, date de sa première rencontre avec l'auteur, et se referme après l'exclusion des Gouin, Hamel et Chaloult du Bloc populaire canadien en 1944. 
Au fil des pages, l'auteur interroge sa mémoire en reprenant des éléments de récits des Groulx, Rumilly, Gagnon, Chaloult, Black et Comeau et réagit en proposant sa propre version des événements ou en châtiant plus ou moins sévèrement le coupable d'une mauvaise interprétation ou d'un récit incomplet causant un préjudice historique à Paul Gouin. Comeau, par exemple, est tantôt excusé parce que simple journaliste (p. 541), tantôt vilipendé parce qu'il a erronément rapporté le décès de l'auteur. Ailleurs, l'auteur s'emploie à rehausser l'importance historique de certains des gestes de son héros. C'est ainsi que le «premier et dernier discours [de Gouin] à la Chambre, l'un des meilleurs de sa carrière» devient «l'un de ces grands moments de notre nation, l'une de ces grandes épopées oratoires qui ont inscrit leur date dans la mémoire de notre histoire» (p. 218-219) et se voit comparé d'emblée à des passages sur la défense des Canadiens français de Lafontaine, de Chapleau et de Mercier.

À première vue, l'ouvrage prend la forme d'un long réquisitoire pro domo dont le but principal, voire la préoccupation essentielle, viserait à expliquer les insuccès de son héros: trahison de ses collègues et de Duplessis, manque de moyens, incompréhension de «notre maître à penser» Lionel Groulx, silences et discipline héritée de sa formation militaire. Mais en fin d'analyse, on en apprend bien peu sur Gouin qui soit inédit ou insoupçonné.

À vrai dire, le véritable héros de ce livre, c'est l'auteur lui-même, et il ne rate aucune occasion de révéler son propre rôle, trop largement ignoré par plusieurs chroniqueurs de cette période. Ainsi, selon ce qu'il rapporte, $\mathbf{M}^{\mathbf{e}}$ Philippe Ferland aurait occupé une place importante dans l'entourage de Gouin et l'organisation de l'Action libérale nationale: d'abord à titre d'animateur des émissions radiophoniques du parti, mais aussi en tant que candidat et militant.

La méprise créée par le titre du livre est d'autant plus regrettable que le personnage et la carrière de l'auteur lui-même - l'«homme de confiance et (...) confident» de Paul Gouin -, ne sont pas dénués d'intérêt. Le lecteur regrettera d'autant plus les limites temporelles de ces mémoires que son auteur a aussi mené une intéressante carrière d'avocat, de professeur de droit, de juge et d'auteur, après l'épisode de l'ALN. En tant qu'ex-militant rangé de l'ALN, il aurait pu témoigner beaucoup plus largement et pertinemment sur des sujets comme la conversion d'une certaine élite nationaliste au duplessisme, $s$ 'il avait écrit directement ou à partir de ses propres références.

Les lecteurs de «réminiscences» comprennent les règles du genre et en pardonnent volontiers les défauts; certains même les recherchent afin de mieux apprécier le point de vue particulier de l'un ou l'autre des acteurs de l'époque. La lecture de cet ouvrage reste quand même laborieuse, parce que de nombreuses omissions et répétitions entachent la crédibilité du récit et trop d'anachronismes en brisent le rythme. Un travail d'édition minimal n'aurait pourtant pas étouffé la spontanéité de l'auteur; au contraire, il aurait corrigé au moins les nombreuses coquilles et fautes de style qui en déparent le texte. Dans ce cas-ci, la maison Guérin n'a pas su remplir son devoir d'éditeur avec la compétence qu'on lui a reconnue ailleurs. Il eut peut-être mieux valu laisser ce manuscrit dans les archives de l'auteur (sous forme d'interview ou 
de texte) et utiliser le budget de cette publication à des fins susceptibles d'accroître notre compréhension de cette époque.

Service des archives

Université McGill

MARCEL CAYA 